\title{
Photorefractive keratectomy: implications of corneal wound healing
}

Photorefractive keratectomy (PRK) with an argon fluoride laser $(193 \mathrm{~nm})$ was developed to alter the refractive power of the eye predictably and permanently. At PRK the central corneal epithelium is debrided mechanically and a disc 4 to $6 \mathrm{~mm}$ in diameter is ablated into the anterior stroma using computer controlled algorithms to control the depth of the wound. Theoretically for corrections of up to -7 dioptres less than $10 \%$ of the axial corneal thickness is removed. ${ }^{1}$ As there is little loss of corneal strength and minimal tissue distortion during surgery, reproducibility is enhanced, producing a potentially superior refractive technique to radial keratotomy.

Initial enthusiasm for PRK was based on the remarkable precision and smoothness of the ablated surface ${ }^{2-4}$ which it was hoped would be translated to an accurate change in refraction. An ideal result would be achieved if the corneal epithelium then assumed the contour of the ablated surface and there was no stromal regeneration. However, it is now apparent that an initial period of overcorrection is followed by regression to a relatively stable refraction and that in a proportion of cases stromal scarring can produce glare and a loss of best corrected visual acuity..$^{5-8}$ Despite the precision of the PRK ablation the accuracy of the final refraction is at present only comparable to radial keratotomy. Accordingly 5 months after PRK approximately $55 \%$ of eyes have an unaided vision of $6 / 6$, while $95 \%$ of eyes with -2.00 dioptres of error are within 1 dioptre of their intended refraction, ${ }^{7}$ but with considerable variation between individuals. ${ }^{578}$ This error in final refraction is due to the normal response of the cornea to an anterior keratectomy, which is to regenerate tissue to restore the integrity of the eye. Anterior stromal haze after PRK is thought to result from light scattered by scar tissue and has been shown to be more severe with increased ablation depth. ${ }^{5-11}$ Gartry et al detected a reduction in corneal transparency in $92 \%$ of patients, of whom $18 \%$ had lost one to two lines of best corrected Snellen acuity 1 year after surgery. ${ }^{7}$ Additionally, if a small ablation zone ( $4 \mathrm{~mm}$ ) is used positive spherical aberration (creating a halo effect) occurs in conditions of reduced illumination as the pupil dilates past the edge of the ablation. ${ }^{57}$ Although these halos can be eliminated by using a larger ablation zone, ${ }^{7}$ this entails an increased depth of ablation with its associated increased risk of haze. ${ }^{8}$

A potential loss of transparency in the optical axis of an otherwise healthy eye must give cause for concern. Unfortunately, topical corticosteroid therapy following PRK has not been demonstrated to reduce subepithelial haze or regression significantly.$^{8}$ Trials are therefore in progress to evaluate different postoperative regimens to minimise scar formation. As modification of the wound healing response may become an integral part of the management of patients following PRK it is opportune to review our current concepts of corneal scar formation.

\section{Wound healing after PRK}

Corneal wound healing passes through a series of well defined stages which are similar following laser or mechanical keratectomy. Tissue destruction stimulates a directed migration towards the wound of activated epithelial cells, fibroblasts, and macrophages which participate in the removal of damaged tissue and the de novo synthesis of ground substance; finally, there is a period of wound remodelling and increased collagen cross linkage in the mature scar. Elements of the healing process can be considered separately.

\section{EPITHELIAL WOUND HEALING}

Epithelial cell slide begins at the edge of the wound after a short latent phase during which structural proteins are synthesised, actin microfilaments polymerised, and damaged cells desquamated. ${ }^{12}$ Hemidesmosomal attachments to the basement membrane are released in a zone of 50 to $70 \mu \mathrm{m}$ from the wound edge allowing these cells to move as a monolayer to cover the defect. This early movement is independent of cellular division ${ }^{1314}$ but cell numbers are subsequently replaced by division and centripetal migration from a population of slow cycling stem cells in the basal layer at the limbus. ${ }^{15-17}$

Although permanent epithelial cell attachments are released during migration, adhesion to the corneal surface is maintained via transient macromolecular focal contacts. The principal components of these transient attachments are the dimeric glycoproteins, fibronectin and laminin, which bind to the type IV collagen of the basement membrane and to an integrin molecule in the cell membrane which in turn is linked to intracellular actin. Sliding cells release plasminogen activators which cleave these temporary focal contacts, ${ }^{18}$ and permanent anchoring filaments of type VII collagen are regenerated when movement is terminated by contact inhibition. ${ }^{19-22}$ Finally, the epithelial layer thins over protuberances and thickens over defects in the stroma - an overall effect that tends to smooth out irregularities in the corneal surface.

The synthesis of new, functional attachment complexes is complete 4 weeks after PRK but in monkey corneas there are still missing, fragmented, and thickened areas of basement membrane after 18 months ${ }^{23-25}$ with regions of the epithelium devoid of type VII collagen anchoring fibrils. ${ }^{26} \mathrm{~A}$ failure to reestablish firm anchoring points contributes to epithelial breakdown ${ }^{27}$ which occurs in $3 \%$ of eyes after PRK, ${ }^{7}$ and may contribute to the small number of patients who have either a foreign body sensation, watering, or tenderness on rubbing the eye up to 2 years following surgery. ${ }^{78}$

\section{STROMAL WOUND HEALING}

Stromal regeneration depends upon a coordinated interaction between epithelial cells and keratocytes. Epithelial cells maintain a protective environment suitable for stromal cell proliferation ${ }^{28}$ and release cytokines that stimulate keratocyte migration and division. ${ }^{29}{ }^{30}$ Fibrin and fibronectin are deposited from the tear film onto the wound and act as a scaffold for the adhesion of neutrophils, macrophages, and lymphocytes. Simultaneously, keratocytes die back in a $200 \mu \mathrm{m}$ zone from the exposed wound surface, ${ }^{31}$ and migrate back to the surface 
of the wound only after an intact epithelial surface has been re-established. The remaining keratocytes undergo fibroblastic transformation, and expansion of the fibroblast population by cell division begins after approximately 48 to 72 hours and reaches a peak after 3 to 6 days as new connective tissue is synthesised. ${ }^{32}{ }^{33}$ Epithelial cells are then gradually displaced upward and their original attachments become incorporated within the scar. ${ }^{26}$ Keratocyte activity returns to normal after 3 months, although hypercellularity of the wound may persist for years.

Corneal transparency is generally believed to depend upon a restriction in the cross sectional diameter and spacing between collagen fibrils to form a regular lattice. This produces destructive interference of scattered incident light but allows transmission of light in a forward direction. ${ }^{34-36} \mathrm{An}$ alteration in collagen or proteoglycan structure would alter this lattice structure and degrade the optical properties of the cornea. An alternative theory suggests that corneal transparency results from the close similarity of the refractive indices of the collagen fibrils and of the ground substance. ${ }^{37}$ The human corneal stroma contains collagen types I, III, V, and VI. ${ }^{38-41}$ Although early immunohistochemical electron microscope studies either failed to detect type III collagen in human cornea ${ }^{42}$ or located it only in isolated fibrils ${ }^{43}$ more recent work suggests that types I, III, and V collagen copolymerise within the same fibrils throughout the stroma. ${ }^{4041}$ This hybrid nature has led to speculation that fibril diameters in the cornea are controlled by the inclusion of one or more of the minor collagens within the predominantly type I fibrils. ${ }^{44}$ Type VI collagen is also a major constituent of the stroma, comprising up to $30 \%$ of the total collagen content, and immunolabelling has identified type VI filaments interconnecting the collagen fibrils throughout the stroma. ${ }^{41}$ Bowman's layer consists of an irregular meshwork of filaments containing collagen types I, III, V, and VI ${ }^{4041}$ and possibly type IV.42

Corneal scar tissue is hazier, less elastic, and has a lower mechanical strength than normal adult stroma. The structural basis for the haziness of corneal scars is disputed, but may derive from an increased cellularity of the scar, vacuolation, or light scattering as a result of altered collagen fibril arrangement. A recent study. of laser ablated rabbit corneas suggests that the relative contribution of each of these factors may depend on the age of the scar tissue. ${ }^{45}$ In the electron microscope, early corneal scar has a vacuolated appearance; while the collagen fibrils have a normal mean diameter but a greater range. ${ }^{4647}$ After an extended period, transparency improves as the spacing between the fibrils approaches normal ${ }^{48}{ }^{49}$ but vacuoles persist in the scar tissue, ${ }^{45}$ and even after 18 months immunohistochemical studies in monkeys indicate increased levels of type III collagen. ${ }^{26}$ Normal collagen cross linkage is not restored ${ }^{50}$ and the remodelling of the scar is therefore never complete.

The constituents of the ground substance are also altered in scar tissue. ${ }^{51} 52$ The ground substance between the collagen fibrils consists mainly of proteoglycans, type VI collagen filaments, ${ }^{39}$ and a number of other proteins and glycoproteins. Proteoglycans (PG) are acidic macromolecules that are formed of at least one sulphated glycosaminoglycan (GAG) bound to a protein core and associated with collagen fibrils at specific axial locations. ${ }^{33}$ The main proteoglycans in the human stroma are keratan sulphate proteoglycan (KSPG, lumican) and dermatan sulphate proteoglycan (DSPG, decorin) with trace amounts of heparan sulphate proteoglycan (perlecan) and laminin. ${ }^{54}$ GAGs are extremely hydrophilic and most of the water present in the intercellular stroma is in the form of solvation water of GAG molecules. They thus play a vital role in the regulation of tissue hydration, collagen fibril diameter, ${ }^{55}$ spacing, ${ }^{56}$ and hence tissue transparency.
Changes in the ground substance in corneal scars can be demonstrated by staining the proteoglycans in full thickness $^{5758}$ or superficial keratectomy wounds. ${ }^{47}$ In early scar tissue the proteoglycan filaments are much larger than normal and contain mostly highly sulphated, high iduronate DSPG ${ }^{59}$ which persists for about 3 months and is associated with a reduction in the concentration of the KSPG. ${ }^{57-60}$ These abnormal proteoglycans may contribute to the high water content and vacuolated appearance, which in turn contributes to the corneal haze. There are other changes in structure. Hyaluronic acid is present in only small quantities in human and rabbit cornea but is deposited in the rabbit cornea after laser keratectomy, ${ }^{61}$ and chondroitin-6-sulphate is not found in normal stroma but is uniformly distributed with chondroitin-4-sulphate in all scar tissue. The significance of these observations has not been established.

In some respects scar formation recapitulates fetal corneal formation. Fibrils secreted in the early stages of scar formation $^{31}$ are similar in diameter to the parallel bundles of fibrils secreted in embryogenesis. ${ }^{62}$ However, there is no longer domain structure superimposed on newly synthesised collagen in scar tissue ${ }^{50}$ and the ratio of interfibrillar type VI collagen to type I collagen is reduced compared with developing cornea. ${ }^{63}$ Activated keratocytes also express fetal surface antigens for approximately 6 weeks after injury. ${ }^{64}$ During the development of the cornea there is normally a change in the component GAGs from DSPG in the fetus to KSPG which is the predominant proteoglycan in the adult of most species.

Resorption and remodelling of damaged collagen is an integral component of wound repair ${ }^{65}$ Resorption is initiated by proteolytic enzymes from polymorphonuclear leucocytes and is continued by macrophages, epithelial cells, and keratocytes. ${ }^{66}$ The degradation of collagen is catalysed at neutral $\mathrm{pH}$ by a group of structurally related metalloproteinases (collagenase, stromelysin, gelatinase). Only very small quantities of type IV collagenase and gelatinase have been detected in the unwounded cornea, suggesting they play a role in the maintenance of the extracellular matrix, ${ }^{67-69}$ but following injury the expression of these enzymes is increased for prolonged periods as they are secreted into the extracellular matrix by epithelial and stromal cells or by invading inflammatory cells. ${ }^{70}$

\section{Regulation of repair and remodelling}

The factors that control the maturation of scar tissue have become the subject of intense scrutiny. In the uninjured cornea there is a balance between cell production and loss, and the levels of stimulatory and inhibitory growth factors. Cells that are injured become activated and produce cytokines. These are potent peptide or glycoprotein regulatory factors that can act as autocrine or paracrine agents to mediate communications between cells and coordinate chemotaxis, cellular proliferation, and protein synthesis. By acting as competence factors or promoters of DNA synthesis they may have a primary action or they may allow a secondary effect. Signal transduction by cytokines is believed to require binding to a cellular receptor, where an active agent may be cleaved, producing stimulation of the cytoplasmic domain of the receptor and activation of cytoplasmic tyrosine kinase. ${ }^{71}$ The signal thus stimulates the transcription of other signalling molecules and mediates the complex biological responses associated with inflammation and wound healing. Indeed, the pattern of cytokines may influence the degree of cellular infiltration in wounds, and the effect of a single agent may vary according to the cellular environment. ${ }^{72}$

In the avascular cornea cytokines are probably derived from macrophages and fibroblasts. ${ }^{74}$ Platelet derived growth factor (PDGF), transforming growth factor beta (TGF- $\beta$ ), basic fibroblast growth factor (FGF), the interleukins (Il-1, 
Il-6, Il-8), and tumour necrosis factor alpha (TNF- $\alpha$ ) all modulate wound healing. ${ }^{74} 75$ TGF- $\beta$ and PDGF in particular are strong chemotactic agents and mitogens for fibroblasts, but they can also block cell differentiation and stimulate gelatinase production. TGF- $\beta$ is auto-inductive in that it is a chemotactic factor for fibroblasts that in turn secrete more TGF- $\beta^{30}$; thus regulatory processes must exist which terminate stromal repair.

The inhibitory processes of corneal repair are understood poorly and may depend on whether the epithelium is stable or injured. ${ }^{76}$ Keratocytes probably secrete factors which inhibit their growth, and secreted TGF- $\beta$ may both stimulate the deposition of extracellular matrix and suppress matrix degrading collagenases. ${ }^{77}$ The complexity of these interrelationships suggests that any modulation of cytokines to control healing would require the use of combination therapies.

\section{The clinical effect of wound healing}

It has been demonstrated in rabbits, ${ }^{78}$ monkeys, ${ }^{79}$ and humans ${ }^{80} 81$ that scar tissue is formed following PRK and that the depth of scar tissue is roughly proportional to the depth of the ablation..$^{82}{ }^{83}$ The scarring is also proportional to ablation depth ${ }^{84}{ }^{85}$ and, although there are large individual variations, ${ }^{578}$ the haze is maximal at 4 to 6 months and then diminishes. ${ }^{578}$ Any figure for the incidence of haze depends upon the definition of the term; Seiler et al reported 'scarring' in as few as $1.8 \%$ of patients with $<6.0 \mathrm{D}$ correction, ${ }^{83}$ while Gartry et al noted the development of 'haze' in as many as $92 \%$ of eyes after $<7 \cdot 0 \mathrm{D}$ correction, of whom $18 \%$ lost Snellen acuity. ${ }^{7}$ Forward scatter from haze results in loss of low (5\%) contrast sensitivity. ${ }^{6}$

Although a large number of patients have undergone PŔK for treatment of myopia, the presentation of systematic follow up data of refraction results is less common. ${ }^{5-118385-89}$ It appears that after an initial overcorrection, which is proportional to the attempted correction, there is a rapid regression in the first 1 to 2 months (owing to epithelial hyperplasia); haze begins to develop 4 to 6 weeks after PRK (possibly as a result of stromal regeneration) and a relatively stable refraction is achieved by 3 to 5 months. ${ }^{57884}$ The accuracy of the procedure is then usually defined as the percentage of eyes within the band \pm 1.0 dioptres of the intended refraction; this definition produces a natural bias toward greater accuracy for the correction of low refractive error. It can thus be expected that $95 \%$ of patients with 2 dioptres of error will achieve this target, but this figure falls to $20 \%$ when 7 dioptre corrections are attempted. ${ }^{7}$ Thus the greater the attempted correction the smaller the number of patients within these limits. There is a relationship between the amount of haze and the regression of refraction (mean correlation $=0.68),{ }^{884}$ suggesting that stromal regeneration is a major source of residual refractive error following PRK. The intensity of the haze is proportional to loss of contrast sensitivity, ${ }^{8}$ moderately correlated with Snellen acuity loss but not proportional to any halo effect. ${ }^{7}$ It is possible that regression is greater when a smaller diameter is used. Sher $e t a^{84}$ reported encouraging results for errors of up to -14.5 dioptres using beam diameter up to $6.0 \mathrm{~mm}$ and a cut depth as great as $230 \mu \mathrm{m}$; other studies in which regression has been a problem have used 3.5 to $4.8 \mathrm{~mm}$ discs. ${ }^{5091}$

Seiler et al have claimed that undercorrection can be treated and scars removed by reablation after 6 months with a low incidence of recurrence, although their figure $(1.8 \%)$ for scarring after PRK was already remarkably low. ${ }^{83}$ However, early repeat PRK ( 3 months post PRK) induced exaggerated response and opacification in monkeys. ${ }^{92}$
The prevention of fibrosis

A number of approaches have been suggested to control scar formation after PRK. Corticosteroids are known to inhibit corneal stromal healing ${ }^{93-99}$ and to reduce the deposition of scar tissue in experimental models of PRK. ${ }^{78} 100$ Topical steroids have been incorporated in most postoperative regimens. ${ }^{596-89}$ It has even been suggested that the administration of steroid can be titrated against the extent of haze and the regression. ${ }^{989}$ The mechanism of this steroid effect is uncertain but may be by prevention of the recruitment of macrophages and lymphocytes to the wound, or via a distinct anti-anabolic effect by reducing DNA synthesis and collagen deposition in activated fibroblasts. ${ }^{96-98} 101$ In a randomised, double masked, prospective study examining the effect of topical corticosteroid at two discrete ablation depths, Gartry et al found a statistically significant improvement in the induced refraction in the steroid treatment group, but this effect was lost after 3 months when steroids were discontinued. For 6.0D ablations the final effect was statistically insignificant in spite of a $0.78 \mathrm{D}$ difference between placebo and control groups, which may be clinically useful. ${ }^{8}$ No effect on haze was found and in view of the known complications the long term use of steroid would seem to be unacceptable.

Antimetabolites such as 5-fluorouracil and mitomycin-C have an established role in preventing fibrosis following drainage surgery for glaucoma, and they enhance the effect of topical steroids following experimental PRK. ${ }^{100}$ However, these agents are toxic both to epithelial cells and to fibroblasts, and topical application could delay epithelialisation. ${ }^{102}$ Their efficacy and safety therefore need to be validated.

Approaches to the prevention of fibrosis which mimic the natural signals to terminate scarring warrant further investigation. For example, recombinant human EGF stimulates epithelial maturation, while neutralising antibodies applied to the wound could reduce the concentration of TGF- $\beta$, the major fibroblastic cytokine of early wound healing. ${ }^{103}$ Similarly, application of $\alpha 2$-macroglobulin to bind TGF- $\beta$ may augment natural cytokine clearance. ${ }^{104}$ Other agents, such as interferon alfa $2 \mathrm{~b}$, which inhibit fibroblast proliferation, migration, and collagenase production are being evaluated.

Any hyperplasia of the corneal epithelium over the bed of a PRK wound will reduce the induced refractive change, and the epithelium tends to be thicker at the edge of an ablation than at the centre.$^{82}$ We are unaware of any method to prevent epithelial hyperplasia in this situation, but we hypothesise that the effect may be reduced by using a larger ablation diameter and blending the transition between the treated and untreated regions of the cornea.

The regenerative response of the cornea is less marked if an intrastromal keratectomy rather than an anterior keratectomy is performed, ${ }^{78}$ suggesting that the fibroblastic stimulus is augmented by epithelial destruction. Laser assisted keratomileusis has therefore been suggested for the correction of higher myopic errors where haze and regression would be greater. ${ }^{105}$

\section{Conclusions}

At present the predictability of PRK can only be described as fair for myopia up to 4 dioptres. If predictability were increased and haze reduced the procedure would supplant all available refractive surgical procedures but at present enthusiasm is ahead of published data, and the maximum follow up is 3 years. However, it must be said that a high proportion of patients are very pleased with the outcome and objective assessment may not provide a true index of satisfaction. In many instances patients are impressed with the reduction, if not the elimination, of their myopia. 
The justification for refractive surgery in an otherwise normal eye must centre on the accuracy of the procedure in the absence of any subsequent functional disability. Stromal regeneration following PRK may produce corneal haze and regression of the induced refraction. Haze is the result of the scattering of light by the deposition of scar tissue. ${ }^{106}$ The major options for the development of PRK are thus to limit the surgery to the correction of low myopia where small amounts of scar tissue are produced, to perform intrastromal ablation, ${ }^{105}$ or to inhibit scar formation. The development of effective methods to control the scar response will determine the impact that this procedure has on ophthalmic practice.

STEPHEN J TUFT

Moorfields Eye Hospital, DAVID S GARTRY

City Road

London EC1V 2PD

IAN M RAWE

Oxford Research Unit,

The Open University,

Foxcombe Hall,

Berkeley Road,

Boars Hill

Oxford OX1 5HR

1 Munnerlyn CR, Koons SJ, Marshall J. Photorefractive keratectomy: a technique for laser refractive surgery. $\mathcal{F}$ Cataract Refract Surg 1988; 14: 46-52.

2 Puliafito CA, Steinert RF, Deutsch TF, Hillenkamp F, Dehm EJ, Adler CM. Excimer laser ablation of the cornea and lens: experimental studies. Ophthalmology 1985; 92: 741-8.

3 Marshall J, Trokel S, Rothery S, Kreuger RR. A comparative study of corneal incisions induced by diamond and steel knives and two ultraviolet radiations from an excimer laser. Brf Ophthalmol 1986; 70: 482-501.

4 Marshall J, Trokel S, Rothery S, Kreuger RR. Photoablative reprofiling of the cornea using an excimer laser: photorefractive keratectomy. Lasers Ophthalmol 1986; 1: 21-48.

5 Gartry DS, Kerr Muir MG, Marshall J. Photorefractive keratectomy with an argon fluoride excimer laser: a clinical study. Refract Cormeal Surg 1991; 7: 420-35.

6 Lohmann CP, Gartry DS, Kerr Muir M, Timberlake GT, Fitzke FW, Marshall J. Corneal haze after excimer laser refractive surgery: objective measurements and functional implications. Eur $\mathcal{F}$ Ophthalmol 1991; 1: 173-80.

7 Gartry DS, Kerr Muir MG, Marshall J. Excimer laser photorefractive keratectomy: 18 month follow-up. Ophthalmology 1992; 99: 1209-19.

8 Gartry DS, Kerr Muir MG, Lohmann CP, Marshall J. The effect of topical corticosteroids on refractive outcome and corneal haze after photorefractive keratectomy. Arch Ophthalmol 1992; 110: 944-52.

9 Seiler T, Kahle G, Kriegerowski M, Bende T. Excimer laser (193 nm) myopic keratomileusis in sighted and blind human eyes. Refract Comeal Surg 1990; 6: 165-73.

10 McDonald MB, Frantz JM, Klyce SD, Salmeron B, Beuerman RW, Munnerlyn CR, et al. One-year refractive results of central photorefractive keratectomy for myopia in the nonhuman primate cornea. Arch Ophthalmol 1990; 108: 40-7.

11 McDonald MB, Frantz JM, Klyce SD, Beuerman RW, Varnell R, Munnerlyn CR, et al. Central photorefractive keratectomy for myopia. The blind eye study. Arch Ophthalmol 1990; 108: 799-808.

12 Crosson CE, Klyce SD, Beuerman RW. Epithelial wound closure in the rabbit cornea. Invest Ophthalmol Vis Sci 1986; 27: 464-73.

13 Kuwabara T, Perkins DS, Coggan DG. Sliding of the epithelium in experimental corneal wounds. Invest Ophthalmol 1976; 15: 4-14.

14 Gipson IK, Anderson RR. Actin filaments in normal and migrating corneal epithelial cells. Invest Ophthalmol Vis $S c i$ 1977; 16: 161

15 Thoft RA, Friend J. The X, Y, Z hypothesis of corneal epithelial maintenance. Invest Ophthalmol Vis Sci 1983; 24: 1442-3.

16 Ebato B, Friend J, Thoft R. Comparison of limbal and peripheral human corneal epithelium in tissue culture. Invest Ophthalmol Vis Sci 1988; 29: 1533-7.

17 Cotsarelis G, Cheng S-Z, Dong G, Sun T, Lavker RM. Existence of slowcycling limbal epithelial basal cells that can be preferentially stimulated to proliferate: implications on epithelial stem cells. Cell 1989; 57: 210-9.

18 Berman $M$. The pathogenesis of corneal epithelial defects. In: Beuerman RW, Crosson CE, Kaufman HE, eds. Advances in applied biotechnology series.

19 Fujikawa LS, Foster CS, Harrist TJ, Lanigan JM, Colvin RB. Fibronectin in healing rabbit corneal wounds. Lab Invest 1981; 45: 120-9.

20 Fujikawa LS, Foster CS, Gipson IK, Colvin RB. Basement membrane components in healing rabbit corneal epithelial wounds: immunofluorescence and ultrastructural studies. $\mathcal{F}$ Cell Biol 1984; 98 : 128.

21 Gipson IK, Spurr-Michaud SJ, Tisdale AS. Hemidesmosomes and anchoring fibril collagen appear synchronously during development and wound healing. Dev Biol 1988; 126: 253-62.

22 Gipson IK, Spurr-Michaud SI, Tisdale AS. Anchoring fibrils form a complex network in human and rabbit cornea. Invest Ophthalmol Vis Sci 1987; 28: 212-20.

23 Khodadoust AA, Silverstein AM, Kenyon KR, Dowling JE. Adhesion of regenerating corneal epithelium. The role of basement membrane. Am $\mathcal{F}$ Ophthalmol 1968; 65: 339-48.

24 Gipson IK, Spurr-Michaud S, Tisdale A, Keough M. Reassembly of the anchoring structures of the corneal epithelium during wound repair in the anchoring structures of the corneal epithelium du

25 Hanna KD, Pouliquen YM, Savoldelli, Fantes F, Thompson KP, Waring $\mathrm{GO}$, et al. Corneal wound healing in monkeys 18 months after excimer laser GO, et al. Corneal wound healing in monkeys 18 months after excim

26 SundarRaj N, Geiss MJ, Fantes F, Hanna K, Anderson SC, Thompson KP, et al. Healing of excimer laser ablated monkey corneas. An immunological evaluation. Arch Ophthalmol 1990; 108: 1604-10.

27 Azar DT, Spurr-Michaud SJ, Tisdale AS, Gipson IK. Decreased penetration of anchoring fibrils into the diabetic stroma. Arch Ophthalmol 1989; 107 1520-3.

28 Gasset AR, Dohlman CH. The tensile strength of corneal wounds. Arch Ophthalmol 1968; 79: 595-602.

29 Woost PG, Brightwell J, Eiferman RA, Schultz GS. Effect of growth factors with dexamethasone on healing of rabbit corneal stromal incisions. Exp Eye Res 1985; 40: 47-60.

30 Wilson SE, Lloyd SA, He Y-G. EGF, basic FGF, and FGF beta-1 messenge RNA production by rabbit corneal epithelial cells. Invest Ophthalmol Vis $S c i$ 1992; 33: 1987-95.

31 Matsuda H, Smelser GK. Electron microscopy of corneal wound healing. Exp Eye Res 1973; 16: 427.

32 Kitano S, Goldman JN. Cytologic and histochemical changes in cornea wound repair. Arch Ophthalmol 1966; 76: 345-54.

33 Dunnington JH, Weimar V. Influence of the epithelium on the healing of corneal incisions. Am f Ophthalmol 1958; 45: 89-95.

34 Maurice DM. The structure and transparency of the cornea. F Physiol 1957, 136: $263-76$.

35 Hedbys BO. The role of polysaccharides in corneal swelling. Exp Eye Res $1961 ; 1: 81$.

36 Benedek GB. Theory of transparency of the eye. Appl Optics 1971; 10: 459.

37 Smith JE. The transparency of the corneal stroma. Vision Res 1969; 9: 393-6.

38 Newsome DA, Gross J, Hassel JR. Human corneal stroma contains three distinct collagens. Invest Ophthalmol Vis Sci 1982; 22: 376-81.

39 Zimmerman DR, Trueb B, Winterhalter KH, Witmer R, Fischer RW. Type VI collagen as a major component of the human cornea. Fed Eur Biochem Soc 1986; 197: 55-8.

40 Marshall GE, Kontas AG, Lee WR. Immunogold fine structural localisatio of extracellular matrix components in aged human cornea. I. Types I-IV collagen and laminin. Graefes Arch Clin Exp Ophthalmol 1991; 229 $157-63$

41 Marshall GE, Kontas AG, Lee WR. Immunogold fine structural localisation of extracellular matrix components in aged human corneal. I. Collagen types V and VI. Graefes Arch Clin Exp Ophthalmol 1991; 229: 164-71.

42 BenEzra D, Foidart JM. Collagens and non-collagenous proteins in the human eye. I. Corneal stroma in vivo and keratocyte production in vitro. Cum Eye Res 1981; 1: 101-10.

43 Keene DR, Sakai LY, Bachinger HP, Burgerson RE. Type III collagen can be present on banded collagen fibrils regardless. $\mathcal{F}$ Cell Biol 1987; 105: 2393-

44 Birk DE, Fitch JM, Babiarz JP, Doane KJ, Linsenmayer TF. Collagen fbrillogenesis in vitro: interaction of types $I$ and $V$ collagen regulates fibri diameter. F Cell Sci 1990; 95: 649-57.

45 Rawe IM, Zabel RW, Tuft SJ, Chen V, Meek KM. A morphological study of rabbit corneas after laser keratectomy. Eye 1992; 6: 637-42.

46 Menasche M, Robert L, Payrau P, Hamada R, Pouliquen Y. Comparative biochemical and morphometric studies on corneal wound healing. Pathologie Biologie 1988; 36: 781-9.

47 Rawe IM, Tuft SJ, Meek KM. Proteoglycan and collagen morphology in superficially scarred rabbit cornea. Histochem f 1992; 24: 311-8.

48 Cintron C, Scheider H, Kublin CL. Corneal scar formation. Exp Eye Res 1973 ; $17: 251-9$.

49 Cintron C, Kublin CL. Regeneration of corneal tissue. Dev Biol 1977; 61: 346-57.

50 Cintron C, Hassinger LC, Kublin CL, Cannon DJ. Biochemical and ultrastructural changes in collagen during corneal wound healing. f Ultrastruct Res 1978; 65: 13-22.

51 Murata Y, Yoshioka H, Kitoaka M, Iyama K, Okamura R. Usuku G. Type VI in healing rabbit corneal wounds. Ophthalmic Res 1990; 22: 144-51.

52 Tervo K, van Setton G-B, Beverman RW, Virtanen I, Tarkkanen A, Tervo T. Expression of tenascin and cellular fibronectin in the rabbit cornea after anterior keratectomy. Invest Ophthalmol Vis Sci 1991; 32: 2912-9.

53 Scott JE, Haigh M. 'Small' proteoglycan-collagen interactions: keratan sulfate protect Biosci Rep 1985; 5: 765-74.

54 Hassell JR, Schrecengost PK, Rada JA, SundarRaj N, Sussi G, Thoft RA. Biosynthesis of stromal matrix proteoglycans and basement membran componts by human corneal fibroblasts. Invest Ophthalmol Vis Sci 1992 33: 547-57.

55 Katz EP, Wachtel EJ, Maroudas A. Extrafibrillar proteoglycans osmotically regulate the molecular packing of collagen in cartilage. Biochim Biophys Acta 1986; 882: 136-9.

56 Borcherding MS, Blacok LS, Sittig RA, Bizzel JU, Breen M, Weinstein HG Proteoglycans and collagen fibre organisation in human corneosclera tissue. Exp Eye Res 1975; 21: 59-70.

57 Cintron C, Covington HI, Kublin CL. Morphologic analysis of proteoglycans in rabbit corneal scars. Invest Ophthalmol Vis Sci 1990; 31: 1789-98.

58 Cintron C, Gregory JD, Damle SP, Kublin CL. Biochemical analysis of proteoglycans in rabbit corneal scars. Invest Ophthalmol Vis Sci 1990; 31 1975-81.

59 Funderburgh JL, Chandler JW. Proteoglycans of rabbit corneas with nonperforating wounds. Invest Ophthalmol Vis Sci 1989; 30: 435-42.

60 Hassell JR, Cintron C, Kublin C, Newsome DA. Proteoglycan changes durin restoration of transparency in corneal scars. Arch Biochem Biophys 1986; 222: 362-9.

61 Fitzsimmons T, Fagerholm P, Schenholm M, Harfstrand A. Hyaluronic acid in the rabbit cornea after superficial keratectomy with the excimer laser. Invest Ophthalmol Vis Sci 1991; 32: 1247.

62 Birk DE, Trelstad RL. Extracellular compartments in matrix morphogenesis: collagen fibril, bundle

63 Cho $\mathrm{H}$ Covington HI Cintron C. Immunolocalization of type VI collagen in developing and healing rabbit cornea. Invest Ophthalmol Vis Sci 1990; 31 $1096-102$

64 SundarRaj N, Anderson S, Barbacci-Tobin E. An intermediate filament associated developmentally regulated protein in corneal fibroblasts. Cur Eye Res 1988; 7: 937-46.

65 Ten Cate AR, Deporter DA. The degenerative role of the fibroblast in the remodelling and turnover of collagen in soft connective tissue. Anat Rec 1975 ; 182: 1-14. . 
66 Graf B, Pouliquen Y, Frouin M-A, de Montaut F. The phenomena of reabsorption in the course of cicatrization of experimental wounds of the cornea (ultrastructural study). Exp Eye Res 1972; 13: 24-32.

67 Gordon JM, Bauer EA, Eisen AZ. Collagenase in human cornea: immunological localisation. Arch Ophthalmol 1980; 98: 341-5.

68 Fini ME, Girard MT. Expression of collagenolytic/gelatinolytic metalloproteinases by normal cornea. Invest Ophthalmol Vis $S c i$ 1990; 31: 1779-88.

69 Fini ME, Matsubara M, Zieske JD, Cintron C, Girard MT, Kublin CL. Type IV collagenase expression in normal cornea and healing corneal wounds. Invest Ophthalmol Vis Sci (suppl) 1991; 32: 1070

70 Brown SI, Weller CA. Cell origin of collagenase in normal and wounded corneas. Arch Ophthalmol 1970; 83: 74-7.

71 Smith JC, Stiles CD. Cytoplasmic transfer of the mitogenic response to platelet-derived growth factor. Proc Natl Acad Sci USA 1981; 78: 4362-3.

72 Johnson-Wint B. Regulation of stromal cell collagenase production in adult rabbit cornea. In vitro stimulation and inhibition by epithelial cell products. Proc Natl Acad Sci USA 1980; 77: 5331.

73 Yue BYJT, Hsieh P, Baum JL. Effects of corneal extracts on rabbit corneal stromal cells in culture. Invest Ophthalmol Vis Sci 1986; 27: 14-9.

74 Deuel TF, Kawahara RS. Growth factors and wound healing: platelet-derived growth factor as a model cytokine. Annu Rev Med 1991; 42: 567-84.

75 McKay IA, Leigh IM. Epidermal cytokines and their roles in cutaneous wound healing Brf Dermatol 1991; 124:513-8.

76 BenEzra D, Tanishima T. Possible regulatory mechanisms of the cornea. I. Epithelial-stromal interaction in vitro. Arch Ophthalmol 1978; 96: 1891-6.

77 Girard MT, Matsubara M, Fini E. Transforming growth factor- $\beta$ and interleukin-1 modulate metalloproteinase expression by corneal stromal cells. Invest Ophthalmol Vis Sci 1991; 32: 2441-54.

78 Tuft SJ, Zabel RW, Marshall J. Corneal repair following keratectomy in the rabbit. Invest Ophthalmol Vis Sci 1989; 20: 1769-77.

79 Fantes FF, Hanna KD, Waring GO, Pouliquen Y, Thompson KP, Savoldell $M$. Wound healing after excimer laser keratomileusis (photorefractive keratectomy) in monkeys. Arch Ophthalmol 1990; 108: 665-75.

80 Wu WCS, Stark WJ, Green WR. Corneal wound healing after 193-nm excimer laser keratectomy. Arch Ophthalmol 1991; 109: 1426-32.

81 Gartry D, Kerr Muir M, Marshall J. Excimer laser treatment of corneal surface pathology: a laboratory and clinical study. Br f Ophthalmol 1991; surface path $258-69$.

82 Sheih E, Moreira H, D'Arcy J, Clapham TN, McDonnell PJ. Quantitative analysis of wound healing after cylindrical and spherical excimer laser ablations. Ophthalmology 1992; 99: 1050-5.

83 Seiler T, Derse $M$, Pham T. Repeated excimer laser treatment after photorefractive keratectomy. Arch Ophthalmol 1992; 110: 1230-3

84 Sher NA, Barak M, Daya S, DeMarchi J, Tucci A, Hardten DR, et al. Excimer laser photorefractive keratectomy in high myopia. Arch Ophthalmol 1992; 110: $935-43$.

85 Liu JC, McDonald MB, Varnell, Andrade HA. Myopic excimer laser photorefractive keratectomy: an analysis of clinical correlations. Refract Comeal Surg 1990; 6: 321-8.

86 Seiler T, Bende T, Wollensak J, Trokel S. Excimer laser keratectomy for correction of astigmatism. Am $\mathcal{F}$ Ophthalmol 1988; 105: 117-24.

87 Zabel RW, Sher NA, Ostrov CS, Parker P, Lindstrom RL. Myopic excimer laser keratectomy: a preliminary report. Refract Cormeal Surg 1990; 6: 329-34.
88 Sher NA, Chen V, Bowers RA, Frantz JM, Brown DC, Eiferman R, et al. The use of the 193-nm excimer laser for myopic photorefractive keratectomy in sighted eyes. A multicentre study. Arch Ophthalmol 1991; 109. 1525-30.

89 Seiler T, Wollensak J. Myopic photorefractive keratectomy with the excimer laser: one-year follow-up. Ophthalmology 1991; 98: 1156-63.

90 McDonald MB, Liu JC, Byrd TJ, Abdelmegeed M, Andrade HA, Klyce SD, et al. Central photorefractive keratectomy for myopia: partially sighted and normally sighted eyes. Ophthalmology 1991; 98: 1327-38.

91 Brancato R, Tavola A, Carones F, Sciaidone A, Gallus G, Fontanella G. Excimer laser photorefractive keratectomy (PRK): first report from the Italian study group. Ital f Ophthalmol 1991; 3: 189-95.

92 Hanna KD, Pouliquen YM, Waring GO, Savoldelli M, Fantes F, Thompson KP: Corneal wound healing in monkeys after repeated excimer laser photorefractive keratectomy. Arch Ophthalmol 1992; 110: 1286-91.

93 Sugar J, Chandler JW. Experimental corneal wound strength. Arch Ophthalmol 1974; 92: 248-9.

94 Phillips K, Arffa R, Cintron C, Rose J, Miller D, Cublin CL, et al. Effects of prednisolone and medroxy-progesterone on corneal wound healing, ulceration, and neovascularisation. Arch Ophthalmol 1983; 101: 640-3.

95 Newell FW, Dixon JM. Effect of subconjunctival cortisone upon the immediate union of experimental corneal grafts. Am $\mathcal{F}$ Ophthalmol 1951; 34: immediate.

96 Polack FM, Rosen PN. Topical steroids and tritiated thymidine uptake. Effect on corneal healing. Arch Ophthalmol 1967; 77: 400

97 Gassett PR, Lorenzetti DWC, Ellison EM, Kaufman HE. Quantitative corticosteroid effect on corneal wound healing. Arch Ophthalmol 1969; 81: 589-91.

98 McDonald TO, Borgmann AR, Roberts MD, Fox LG. Corneal wound healing: 1. Inhibition of stromal healing by three dexamethasone derivatives. Invest Ophthalmol 1970; 9: 703-11.

99 Newsome DA, Gross J. Prevention by medroxyprogesterone of perforation in the alkali-burned rabbit cornea: inhibition of collagenolytic activity. Invest Ophthalmol Vis Sci 1977; 16: 21-31.

100 Talamo JH, Gollamudi S, Green WR, De La Cruz Z, Filatov V, Stark WJ. Modulation of corneal wound healing after excimer laser keratomileusis after using topical mitomycin C and steroids. Arch Ophthalmol 1991; 109: after using $1141-6$.

101 Blumenkranz MS, Claflin A, Halek AS. Selection of therapeutic agents for intraocular proliferative disease. Arch Ophthalmol 1984; 102: 598-604.

102 Rubinfeld RS, Pfister RR, Stein RM, Foster CS, Martin NF, Stoleru S, et al. Serious complications of topical mitomycin-C after pterygium surgery

103 Shah M, Foreman DM, Ferguson MWJ. Control of scarring in adult wounds by neutralising antibody to transforming growth factor $\beta$. Lancet 1992; 339: $213-4$.

104 Huang SS, O'Grady P, Huang JS. Human transforming growth factor $\beta-\alpha 2$ macroglobulin complex is a latent form of TGF $\beta$. $\mathcal{F}$ Biol Chem 1988; 263 . $1525-41$.

105 Buratto L, Ferrari M, Rama P. Excimer laser intrastromal keratomileusis. Am f Ophthalmol 1992; 113: 291-5.

106 Lohmann C, Gartry D, Kerr Muir M, Timberlake G, Fitzke F, Marshall J. 'Haze' in photorefractive keratectomy: its origins and consequences. Laser Light Ophthalmol 1991; 4: 15-34. 